\title{
ANALYSIS OF MACHINE AVAILABILITY AT SURFACE-MOUNT TECHNOLOGY (SMT) LINE USING WITNESS SIMULATION
}

\author{
Kam Sheng Mak and Hasnida Ab-Samat \\ School of Mechanical Engineering, Engineering Campus, Universiti Sains Malaysia (USM), Pulau Pinang, \\ Malaysia, Tel: +6012-9235412, e-mail: hasnida@usm.my
}

Received Date: October 13, 2019; Revised Date: April 23, 2020; Acceptance Date: August 6, 2020

\begin{abstract}
In the competition to excel in the Industrial 4.0 race, companies especially in Semiconductor Industry, strive to attain efficiency by removing process bottlenecks, improving productivity and increasing machine availability during operation. As so, this research was conducted to analyze the machine's availability based on various preventive maintenance (PM) scheduling. A model was developed in WITNESS 14 Manufacturing Performance Edition software to imitate the Surface-mount Technology (SMT) line in a manufacturing system. The model was build based on a serial layout of five machines which are a screen printer, glue dispenser, chip shooter, pick and place and reflow oven. Then, the simulation was run to study the availability of each machine with relation to different stoppages intervals and duration based on the selected PM schedule. The findings of this project show that PM for an SMT line should be carried out every week with 30 minutes PM duration to achieve high machine availability and minimal machine downtime.
\end{abstract}

Keywords: Availability, Preventive maintenance (PM), Simulation, Surface-mount technology (SMT), WITNESS

\section{Introduction}

Exponential advances in technology have pushed companies to its limits in delivering innovative and quality products at the lowest cost possible. Therefore, one of the effective solutions is by minimizing machine downtime in manufacturing operations, which provides a range of benefits like maximized efficiency and higher profits. Machine stoppages and downtime is a major factor that hinders the attainment of manufacturing efficiency [1]. It leads to the held-up of the manufacturing process and disrupts the workflow. The cost for the machine downtime is enormous when calculated based on the cost of labor rendered idle by the unavailability of the machinery. The company also needs to pay the overtime cost for maintenance personnel. In some cases, the company may be forced to delay its product shipments because of machine breakdown; hence, the surcharges will be applied for the lateness. The situation is critical and can be viewed as in the Surface-mount technology (SMT) line which runs in series and continuous configuration.

SMT is an assembly process of complex circuitry fitting in small spaces. The process is used to mount electronic components on the surface of printed circuit boards [2]. The components need to be directly mounted onto the printed circuit board rather than wired or inserted through 
holes enabling more electronics components to be inserted into small spaces hence reducing devices size and weight. SMT produces Surface-mount Devices (SMDs) which are widely used in today's industry. In the SMT line, five different machines are connected by conveyors. Since the process of SMT is a continuous process, the whole production line will stop when one of the machine breakdown [3]. This will cause the other machines to go into an idle state. Therefore, reducing machine availability and affecting production output.

Since the production line must run smoothly without breakdown, proper maintenance is essential for today's production systems [4]. Machine downtime will affect the throughput in the production line. If a machine is idle, then the products not being produced, this will certainly affect the business's bottom line. Minimizing downtime also affects a company's profits, making it crucial that the maintenance system was designed to reduce both maintenance and inventoryrelated costs [5]. Therefore, effective maintenance planning is one of the methods to achieve high productivity and breakdown prevention [1]. To keep the system in good condition and increase machine availability, maintenance management is an important policy in a repairable system [6].

Maintenance is a practice in various techniques and strategies as reviewed by [3]. Maintenance recovers and improves equipment performance, and is an important part of a product life cycle [7]. From the information that gets from the computer system, maintenance workers can do their works effectively. For instance, the worker can prepare the spare parts needed in the maintenance time. Thus, they can save a lot of time when doing maintenance. For this project, the scope of work focus on Preventive Maintenance (PM) scheduling as it is the most common and basic maintenance technique practiced in the industry.

PM is defined as regularly scheduled maintenance actions based on average failure rates. An optimized PM strategy can provide many benefits to an organization in terms of extending equipment life and machine availability. Properly scheduled PM can help to maintain the production system in top operating conditions to minimize operating costs [8]. According to [9] impact of PM on the service level of degrading manufacturing systems will affect the completion time and delivery dates of customer orders. In the majority of maintenance scheduling studies, the machines were assumed continuously available with perfect maintenance. However, the resources are subject to stoppages and downtime periods because of various planned resources such as PM duration and interval.

Meanwhile, in the age of Industry 4.0, simulation modelling is an important method of analysis, which can be used easily to verify, communicate and understood the real system. Simulation is the "imitation of the real-world process or system over time" which is sufficient enough to demonstrate and illustrate the real industry using software with certain adequate accuracy [2]. Computer simulation is used in industry to conducting experiments on a real system that is impossible or impractical. Many costs and times can be saved through the simulation. This is because the simulation is less expensive than building and testing hardware prototypes. According to the simulation output, the production process can be verified by conducting the additional experiment [10].

Simulation can also be used to forecast the future behavior of a system and investigate what can be done to influence that future behavior. Therefore, necessary changes can be identified 
to improve the system. Other benefits of using simulation software are such as risk-free environment, save money and time, visualization, insight into dynamics, increased accuracy and handle uncertainty. The use of simulation to verify and validate process automation systems, perform software acceptance tests and train operators provides numerous benefits to companies in the manufacturing industries [11]. Analysis based on simulation can reduce the risk of unplanned machine breakdowns where the researcher can plan and schedule operation based on the simulation analysis [7]. Hence, simulation enables the user to illustrate the condition to schedule and predict the maintenance system without interrupting the operation.

\section{Methodology}

In order to achieve the research objectives, a process flow of research methodology was developed as shown in Figure 1.

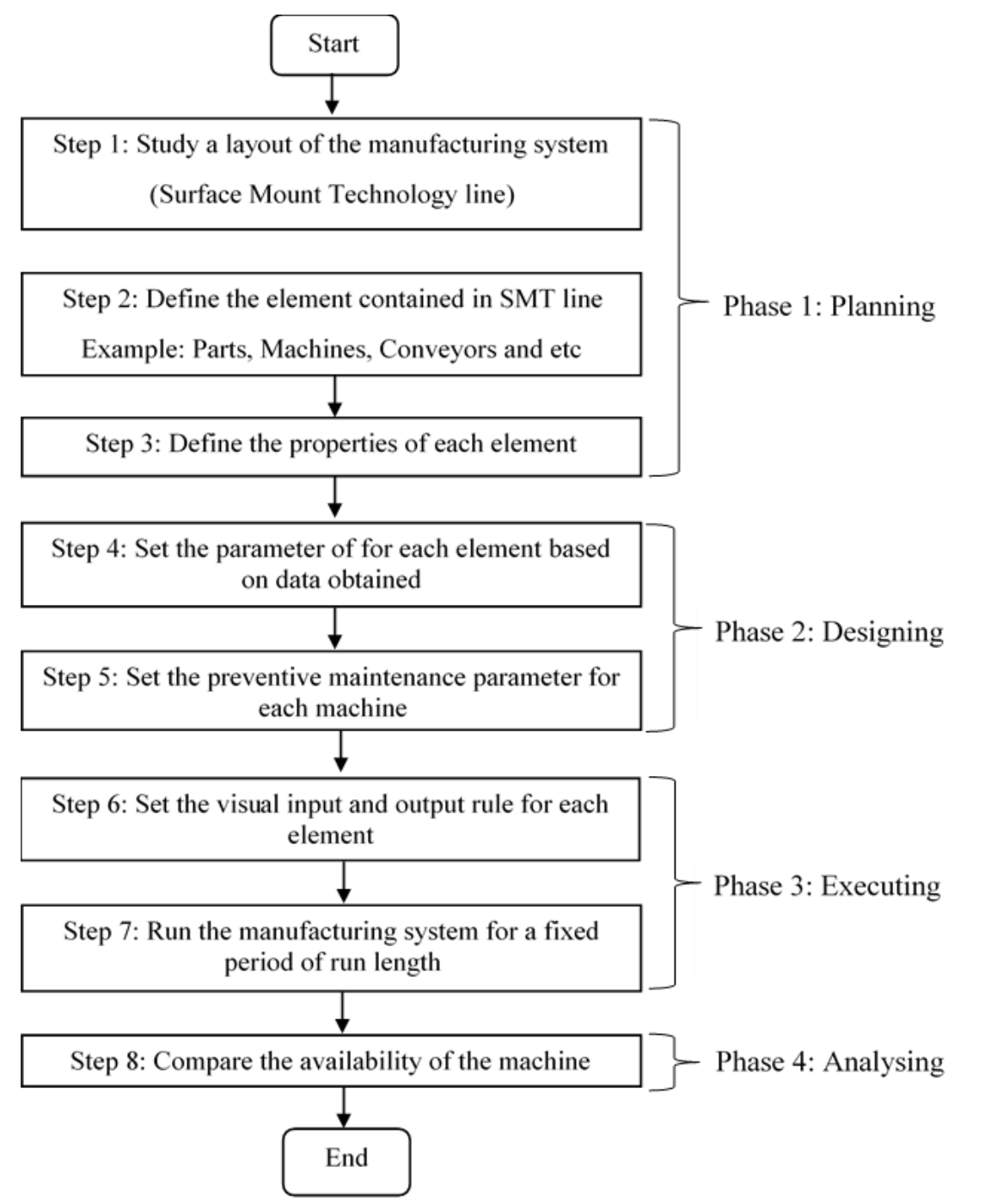

Figure 1. Steps in four phases of research methodology 
This research was conducted in four phases with eight steps. Phase 1 focuses on studying and understanding PM scheduling and the SMT operation, and Phase 2 conducted to collects data like machine and maintenance parameters to design the model in WITNESS simulation. Then, Phase 3 involves imitating the operation with a few options in PM schedules. Simulation application is fundamental for enhancing production systems and reduction of bottleneck occurrences [4] and to achieve the result in term of production output, machine downtime and availability function. Finally, Phase 4 involves steps in analyzing the results from the previous phase to achieve the research objectives.

There are a few simulation software used for production lines like SIMUL8 basic, Arena and Witness. Witness was chosen for this project as it can be used to models real processes can be emulated already within the planning phase and used for experiments. Witness has some special features like modular structure and building block design and 3D visualization. The software package used to simulate the model was Witness Simulation Educational Version Release 14 (Build 2124) by the Lanner group. Witness is a simulation tool for dynamic process simulation of manufacturing and business process in 2D or 3D models. The benefits of using Witness software enable users to develop a feature of model rapidly, analyze business environments to deliver improved process performance, optimized use of resources and conduct comprehensive experimentation, optimization \& reporting framework.

The software helps to decrease the risk by enabling the model of the work environment and simulate the consequences of different decisions. Users can propose the right solution for a company with displaying in virtual reality environment and information change with the presence of the Witness simulation tool. Witness software also helps the user in predicting and solving problems related to production bottlenecks, overly idle resources [4]. The simulation of the model of this research is based on the SMT line, located in the Business Unit Innovation Centre, School of Mechanical Engineering, Universiti Sains Malaysia (USM). Table 1 shows the elements of the SMT line.

Table 1. Types of Elements

\begin{tabular}{cl}
\hline Designer Element & \multicolumn{1}{c}{ Characteristics } \\
\hline Machine & Part representing Printed Circuit Board (PCB) produced. \\
\hline Labor & $\begin{array}{l}\text { In this research, there are a total of five machines used in the SMT line } \\
\text { which is, Solder Paste Screen Printer, Glue Dispenser, Chip Shooter, and } \\
\text { Place Machine and Reflow Oven. }\end{array}$ \\
\hline Conveyor & $\begin{array}{l}\text { There are two types of labour: } \\
\text { - The operator that in charge of minor issues such as feeder problems. }\end{array}$ \\
\hline
\end{tabular}


In real manufacturing system, the properties of an element depend on the field of manufacturing. For SMT production line, there was a straight line connecting all the machines made the process continuous flow. Most of the machine is a single type machine since only one input move in and one output come out. The machine only can process one part once. Reflow oven contains multiple zones, which can be individually controlled for temperature. Therefore, when the first PCB reaching the second zones of the reflow oven, the next PCB can enter the first zones. Hence, multiple station machine properties are used in the simulation. The full descriptions of the model are listed in Table 2. Meanwhile, Figure 2 shows the processes in the SMT line and layout of the model in witness software.

Table 2. Properties and Type of Elements Used in the Simulated Model

\begin{tabular}{|l|l|l|}
\hline Element & Properties & Description \\
\hline Printed Circuit Board & Passive Type & $\begin{array}{l}\text { The part was pulled from the first } \\
\text { machine according to customer demand. } \\
\text { Screen printer will pull NEXT batch of } \\
\text { PCB if one batch of an order has shipped. }\end{array}$ \\
\hline $\begin{array}{l}\text { Screen Printer } \\
\text { Glue Dispenser } \\
\text { Pick and Place }\end{array}$ & Single type of machine & $\begin{array}{l}\text { PCB must come out first before the next } \\
\text { PCB moved into the machine }\end{array}$ \\
\hline $\begin{array}{l}\text { Reflow Oven } \\
\text { Nutek Linking }\end{array}$ & $\begin{array}{l}\text { Multiple station } \\
\text { machine }\end{array}$ & $\begin{array}{l}\text { Multiple units inside the machine were } \\
\text { possible since there have different } \\
\text { temperature zones in the reflow oven. } \\
\text { Another PCB can enter before the next } \\
\text { unit come out. }\end{array}$ \\
& $\begin{array}{l}\text { Type: Continuous } \\
\text { Queuing } \\
\text { Length:1m } \\
\text { Speed:14m/min } \\
\text { Maximum Capacity:4 }\end{array}$ & $\begin{array}{l}\text { The conveyor used as a continuous } \\
\text { queuing type which can transfer the PCB } \\
\text { continuously. }\end{array}$ \\
\hline
\end{tabular}

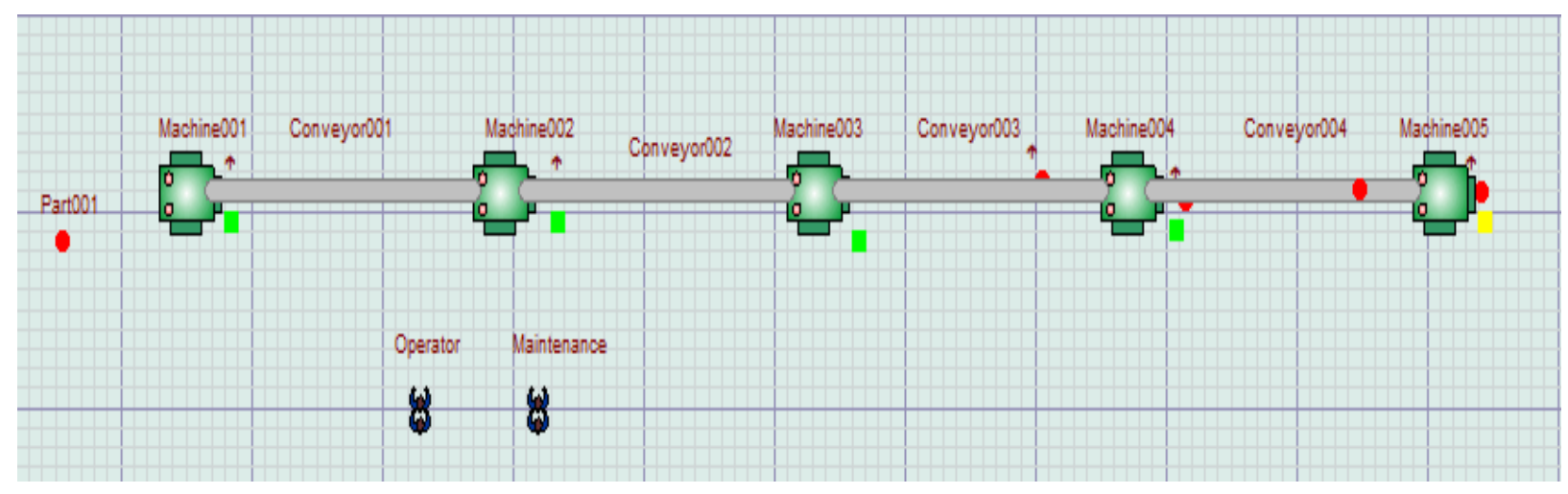

Figure 2. The layout of the model in Witness Software 
The cycle time data were obtained from many sources such as machine manual and analogous manufacturing company and as shown in Table 3 .

Table 3. Process Parameter for Each Machine

\begin{tabular}{|l|c|}
\hline \multicolumn{1}{|c|}{ Machine } & Cycle Time (min) \\
\hline Machine 001- Screen Printer & 0.25 \\
\hline Machine 002- Glue Dispenser & 0.25 \\
\hline Machine 003- Chip Shooter & 0.24 \\
\hline Machine 004- Pick and Place & 0.23 \\
\hline Machine 005- Reflow Oven & 1.61 \\
\hline
\end{tabular}

It is crucial to have access to accurate and timely data to be able to understand the extent of downtime and its root causes. There are two types of downtime: planned downtime and unplanned downtime. Planned downtime involves important stoppages like setup, changeover, breaks, etc., but unplanned disruptions in the production can end up costing significant time and money [1]. The company needs to implement a regular maintenance schedule to prevent machine stoppages and breakdown. In demanding factories, regular maintenance will be easily neglected due to high production. To prevent this, PM scheduling must be a practice for personnel in the company. If a company wants a delivery that has $24 / 7$ availability, minimizing downtime as much as possible is necessary.

Availability is a metric that combines the concepts of reliability and maintainability. Availability deals with the duration of up-time for operations and is a measure of how often the system is alive and well. Hence, the run length in simulation for this research was set as three months (129600 minutes). In this project, there are few options used in the simulation which are 1 month 2 days PM, 2 weeks 1 day PM, 10 days half-day PM, 1 week 30 minutes PM, twice a week 30 minutes PM and 1 day 15 minutes PM. Table 4 details the breakdown interval and PM duration set in this research.

Table 4. Breakdown Interval and PM Duration

\begin{tabular}{lc}
\hline Breakdown Interval (min) & PM Duration (min) \\
\hline 1 month (43200) & 2 days (2880) \\
\hline 2 weeks (20160) & 1 day (1440) \\
\hline 10 days (14400) & Half-day (720) \\
\hline 1 week (10080) & 30 \\
\hline Twice a week (5040) & 30 \\
\hline 1 day (1440) & 15 \\
\hline
\end{tabular}


The simulation method is used in this research to estimate system availability and its associated measures. These include the number of failures and the number of expected maintenance needed. A simulation model of the system could be developed that emulates the random failures and repair times of the components in the system, thus researcher can analyze the suitable time and duration for effective maintenance in operation. In Witness simulation, Mean Time Between Failure (MTBF) and Mean Time to Repair (MTTR) was used to set the maintenance parameter that represented the time between machine failure and repair time [12]. For example, a long breakdown needed for the machine that runs for a very long duration. When the machine runs for a long time, the PM time will be higher since the tool wear is higher. Therefore, optimization should be done to get a suitable PM time.

\section{Results and Discussion}

The purpose of this research is to reduce machines stoppage and downtime. Thus, the results were based on machine downtime and machine availability. In theory, the availability of the machine will decrease with the increase in the machine stoppage. Figure 3 shows the operating time and various situations for the machines in the SMT line. Meanwhile, Figure 4 shows the percentage of total machine availability concerning different PM frequencies and intervals as listed in Table 3 previously. The SMT line is continuously running form the first machine to the last machine. Therefore, the availability of the machine must be calculated from the first machine until the last machine.

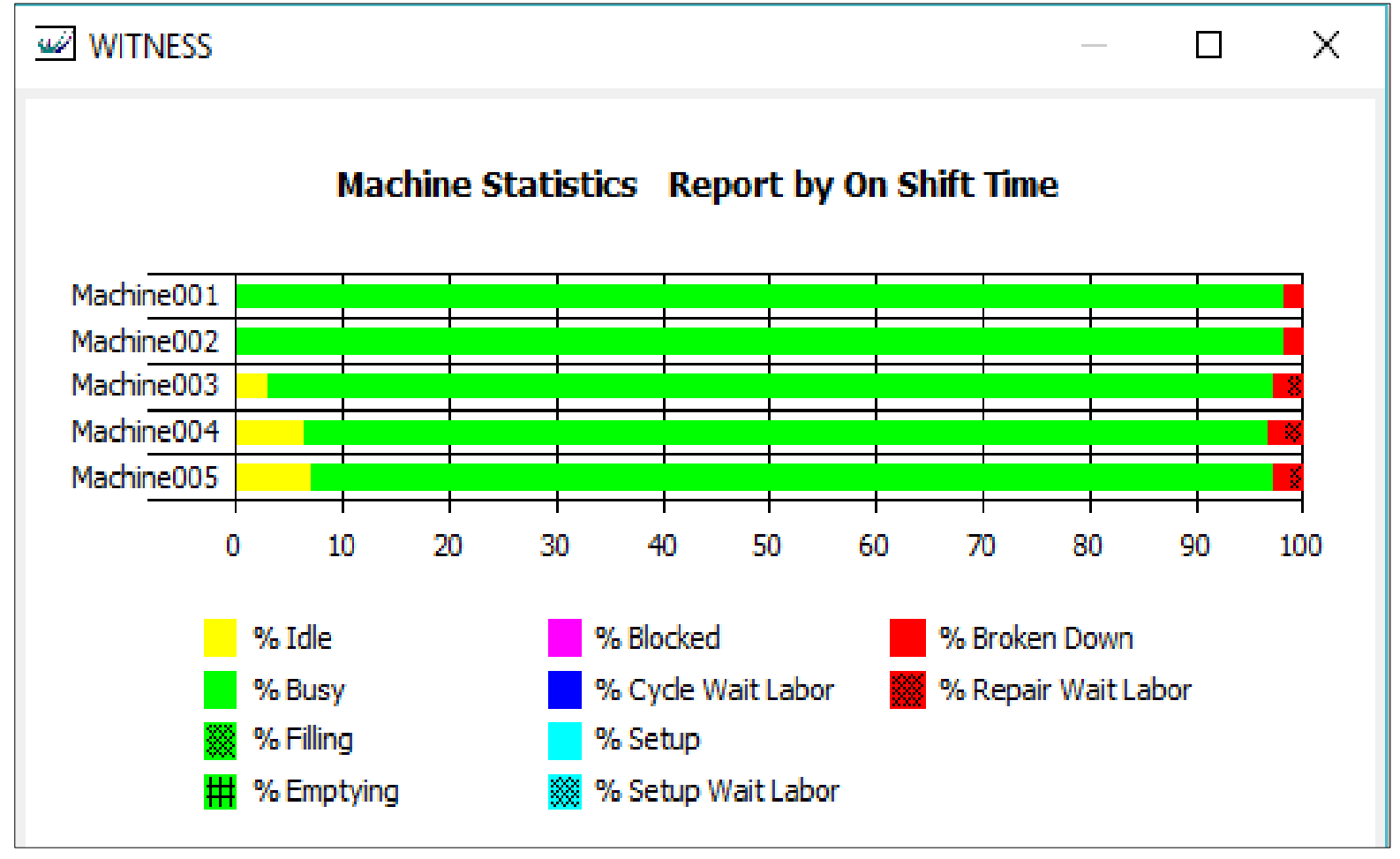

Figure 3. Statistics from Witness simulation 


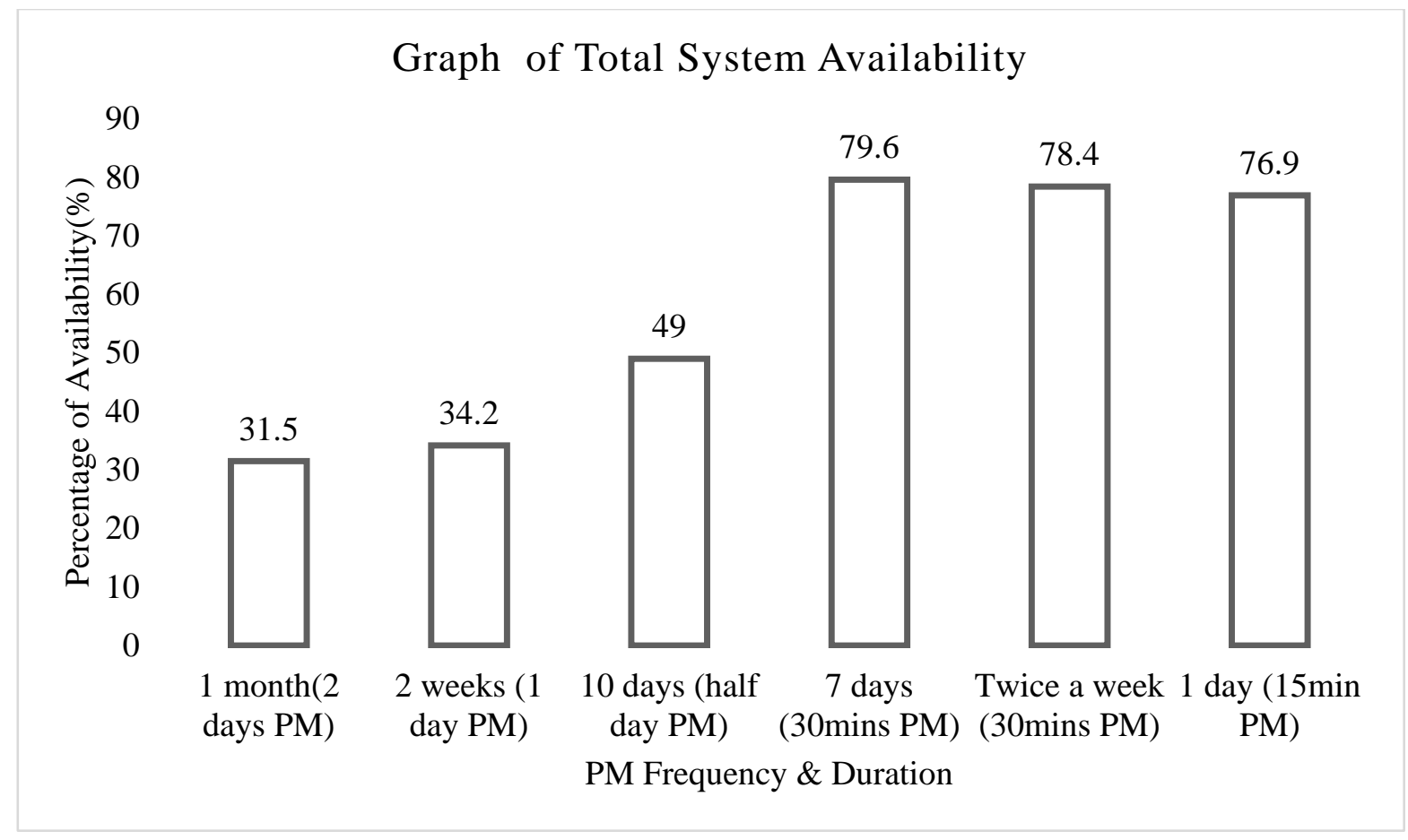

Figure 4. Total SMT line availability based on PM frequency and duration

Total system availability showed the highest percentage of availability is $79.6 \%$ that is every one week 30 minutes PM. The lowest percentage of availability is $31.5 \%$ that is every one month 2 days PM. This is because when the machine didn't do the maintenance for a long period, a long time is needed for doing the maintenance. Production stops for two days will cause the machine to idle for a long time. The products that produce will low due to the long breakdown time. The availability is $34.2 \%$ for every 2 weeks 1 day PM, $49 \%$ for every 10 days 12 hours PM, 78.4\% for twice a week 30 minutes PM and every one day 15 minutes PM. To get the highest machine availability, optimization of scheduling preventive maintenance must be carried out. A too frequency of preventive maintenance can also impact machine availability. From the simulation results, the optimal preventive maintenance is every one week 30 minutes PM due to the highest machine availability shown.

Initially, the hypothesis for this research is that frequent PM activities will lower the machine's availability. However, results from the simulation show the opposite as PM reduces unplanned stoppages and downtime. Therefore, the optimization of PM is very important for the production line. The PM schedule must be plan wisely to get the highest availability of the machine. In comparison, the highest overall equipment efficiency that gets from previous research is $95.10 \%$ by using the 10000 minutes breakdown interval and 135 minutes PM [7]. This also means that the availability of using this approach should be the highest. However, the availability calculated from the simulation is $74.06 \%$, which is less than the optimum maintenance scheduling. There is an availability difference of $5.54 \%$ compared to optimum maintenance scheduling. Based on the simulation results, the availability from previous research have some difference due to the previous research is based on the wafer fab company. 
Different fields of manufacturing systems will have different PM scheduling. Thus, the maintenance schedule for every field should be carried out in simulation before implementation

\section{Conclusions}

Machine breakdown and stoppage always happened in the industry if the maintenance schedule was not arranged properly. For most manufacturers, downtime is the single largest source of lost production time. Focusing improvements effort on the constraint ensures optimal use of the resources and is the most direct route to improved productivity and profitability. Therefore, companies need good maintenance systems to prevent machine breakdown and stoppage. This research project has brought the insight of the series SMT production line with the focus on various PM scheduling intervals and durations to increase machine availability. The critical issue with the SMT line is a single machine breakdown automatically leads to the whole production line halt and loss of operation. In summary, the most optimal scheduling has been carried out by using the simulation. A frequent PM not necessary is the lowest availability of this research. Every machine has a lifecycle, hence the maintenance must plan to make the machine long-lasting. Based on the simulation, the results showed that every one week 30 minutes PM is the optimize maintenance schedules. The longest PM time has caused the machine availability to become the lowest since the machine did not perform maintenance for a long period. The usage of Witness simulation in this research allows programming language to be inserted for improvement of the maintenance schedule. The model was developed and simulated similar to manufacturing system in real industries which allow, industrial to test a few situations and refer to achieve the best effectiveness and availability.

\section{References}

[1] H. Ab-Samat, S. Kamaruddin, and I.A. Azid, "Maintenance performance measurement: A review," Pertanika Journal of Science and Technology, Vol. 19, No. 2, pp. 199-211, 2011.

[2] S.M. Tan, J.Q. Hwang, and H. Ab-Samat, "WITNESS simulation of preventive and corrective maintenance for Surface Mounted Technology (SMT) line," IOP Conference Series: Materials Science and Engineering, Vol. 505, No. 1, p. 012047, 2019.

[3] E.I. Basri, I.H. Abdul Razak, H. Ab-Samat, and S. Kamaruddin, "Preventive maintenance (PM) planning: A review," Journal of Quality in Maintenance Engineering, Vol. 23, No. 2, pp.114-143. 2017.

[4] P.L. Markt, and M.H. Mayer, "WITNESS simulation software: A flexible suite of simulation tools," In: Winter Simulation Conference: Proceedings of the $29^{\text {th }}$ Conference on Winter Simulation, Institute of Electrical and Electronics Engineers (IEEE), Vol. 7, No. 10, 1997.

[5] R. Sarker, and A. Haque, "Optimization of maintenance and spare provisioning policy using simulation," Applied Mathematical Modelling, Vol. 24, No. 10, pp. 751-760, 2000.

[6] $\mathrm{H} . \mathrm{Xu}$, and $\mathrm{W} . \mathrm{Hu}$, "Modelling and analysis of repairable systems with preventive maintenance," Applied Mathematics and Computation, Vol. 224, pp. 46-53, 2013. 
[7] A.S. Charles, I. Floru, C. Azzaro-Pantel, L. Pibouleau, and S. Domenech, "Optimization of preventive maintenance strategies in a multipurpose batch plant: Application to semiconductor manufacturing," Computers \& Chemical Engineering, Vol. 27, No. 4, pp. 449-467, 2003.

[8] G. Liao, "Optimum policy for a production system with major repair and preventive maintenance," Applied Mathematical Modelling, Vol. 36, No. 11, pp. 5408-5417, 2012.

[9] A. Angius, M. Colledani, L. Silipo, and A. Yemane, "Impact of preventive maintenance on the service level of multi-stage manufacturing systems with degrading machines," IFACPapersOnLine, Vol. 49, No. 12, pp. 568-573, 2016.

[10] B. Bako, and P. Božek, "Trends in simulation and planning of manufacturing companies," Procedia Engineering, Vol. 149, pp. 571-575, 2016.

[11] E.M. Frazzon, L.D. Silva, and M.C. Pires, "Simulation-based performance evaluation of a concept for integrating intelligent maintenance systems and spare parts supply chains," IFAC-PapersOnLine, Vol. 49, No. 12, pp. 1074-1079, 2016.

[12] A.K. Jain, "An optimal preventive maintenance strategy for efficient operation of boilers in industry," International Institute for Science, Technology, and Education, Vol. 2, No. 4, pp. $1-3,2012$. 